\title{
DAMPAK DEKRUITMEN, MUTASI, DAN PENGEMBANGAN ORGANISASI TERHADAP MOTIVASI KERJA KARYAWAN PT. PERKEBUNAN NUSANTARA IX (PERSERO) PG. REJOSARI MAGETAN
}

\author{
SUPRIHATI \\ STIE AAS Surakarta \\ Email : suprihati18@yahoo.co.id
}

\begin{abstract}
ABSTRAK
Tujuan Penelitian ini adalah untuk menganalisis pengaruh dekruitmen, mutasi, dan pengembangan organisasi terhadap motivasi kerja karyawan PT. Perkebunan Nusantara IX (Persero) PG. Rejosari, dan menganalisis faktor yang paling dominan dalam mempengaruhi motivasi kerja karyawan PT. Perkebunan Nusantara IX (Persero) PG. Rejosari, Magetan.

Dalam dalam penelitian ini menggunakan satu model regresi logistik binary dengan rumus $Y=\beta_{0}+\beta_{1} X_{1}+\beta_{2} X_{2}+\beta_{3} X_{3}+v$. Koefisien regresi 16ogistic diketahui bahwa semua variabel independen berpengaruh signifikan terhadap variabel motivasi kerja karyawan. Menurut prediksi karyawan yang merasa memiliki motivasi rendah dengan kode nol (0) adalah 16 responden, sedangkan observasi keseluruhan sebanyak 19. Jadi ketepatan klasifikasi $84,2 \%(16 / 19)$, sedangkan prediksi karyawan yang merasa memiliki motivasi tinggi dengan kode satu (1) ada 48 responden, sedangkan hasil observasi keseluruhan sebanyak 50 jadi ketepatan klasifikasi $96 \%(48 / 50)$ atau secara keseluruhan ketepatan klasifikasi adalah 92,8\% (92,8/100).

Pada penelitian ini menghasilkan bahwa Variabel dekruitmen, mutasi, dan pengembangan organisasi mempunyai pengaruh yang positif dan signifikan terhadap motivasi kerja, yang ditunjukkan dengan nilai chi square Hosmer and Lemeshow Test sebesar 5,173 dan nilai sig Hosmer and Lemeshow test yang sebesar 0,739 dan variabel pengembangan organisasi memberikan sumbangan pengaruh yang paling besar terhadap motivasi kerja dibandingkan dengan variabel dekruitmen dan mutasi, hal ini ditunjukkan dengan nilai koefisien beta sebesar 0,679 dan nilai ekspektasi B sebesar 1,972.
\end{abstract}

Kata Kunci : Dekruitmen, Mutasi, Pengembangan Organisasi, Motivasi 


\section{LATAR BELAKANG MASALAH}

Setiap individu memiliki kondisi internal, di mana kondisi internal tersebut turut berperan dalam aktivitas dirinya sehari-hari. Salah satu dari kondisi internal tersebut adalah "motivasi". Motivasi merupakan proses memengaruhi atau mendorong dari luar terhadap seseorang atau kelompok kerja agar mereka mau melaksanakan sesuatu yang telah ditetapkan. Motivasi atau dorongan (driving force) dimaksudkan sebagai desakan yang alami untuk memuaskan dan mempertahankan kehidupan. Motivasi merupakan pekerjaan yang dilakukan oleh manajer dalam memberikan inspirasi, semangat, dan dorongan kepada orang lain, dalam hal ini karyawannya, untuk mengambil tindakan-tindakan tertentu. Pemberian dorongan ini bertujuan untuk menggiatkan orang-orang atau karyawan agar mereka bersemangat dan dapat mencapai hasil yang dikehendaki oleh orangorang tersebut.

Motivasi juga dapat dikatakan sebagai perbedaan antara dapat melaksanakan dan mau melaksanakan. Motivasi lebih dekat pada mau melaksanakan tugas untuk mencapai tujuan. Motivasi adalah kekuatan, baik dari dalam maupun dari luar yang mendorong seseorang untuk mencapai tujuan tertentu yang telah ditetapkan sebelumnya. Motivasi dapat diartikan sebagai dorongan mental terhadap perorangan atau orang-orang sebagai anggota masyarakat. Motivasi dapat juga diartikan sebagai proses untuk mencoba memengaruhi orang atau orangorang yang dipimpinya agar melakukan pekerjaan yang diinginkan, sesuai dengan tujuan tertentu yang ditetapkan lebih dahulu.

Dari berbagai sumber daya yang dimiliki oleh perusahaan, sumber daya manusia tetaplah menempati kedudukan paling strategik dan penting di antara sumber-sumber daya lainnya. Sumber daya manusialah yang mengalokasikan dan mengelola segenap sumber daya lainnya tersebut. Dengan demikian, bagaimanapun berlimpahnya kondisi sumber-sumber daya yang lain, tanpa didukung oleh sumber daya yang berkualitas maka semakin lama sumber daya lain yang dimilikinya semakin berkurang. Sebaliknya, terbatasnya sumber-sumber daya yang lain apabila didukung oleh sumber daya manusia yang kompeten, masih saja tersisa harapan untuk tetap survive di celahcelah sengitnya persaingan bisnis dewasa ini. Sejarah kehancuran dan keberhasilan perusahaan-perusahaan 
terkemuka di dunia ini tidak terlepas dari arti penting yang inheren dalam sumber daya manusia.

Karena pentingnya sumber daya manusia dalam kehidupan organisasi, maka sudah sewajarnya bila pimpinan organisasi selalu menekankan pada pentingnya motivasi bagi seorang karyawan dengan melakukan berbagai cara. Pengurangan karyawan secara transparan sebagai akibat dari tindakan efisiensi organisasi dapat mendorong seorang karyawan untuk bekerja lebih baik dengan harapan organisasi tidak akan melakukan pengurangan karyawan (dekruitmen).

Mutasi merupakan suatu langkah bagi perusahaan untuk membuat suasana baru bagi karyawan, terlebih mutasi yang disertai dengan peningkatan karir cenderung akan memberikan dorongan kepada karyawan untuk bekerja lebih baik. Namun mutasi yang tidak berdasarkan pertimbangan matang dapat berakibat menurunnya motivasi kerja karyawan, karena mutasi mempunyai dampak yang luas, bukan hanya terhadap karyawan yang bersangkutan saja, tetapi juga terhadap keluarga karyawan yang bersangkutan.

Dalam menghadapi lingkungan yang berubah, organisasi bisnis perlu terus mengembangkan dirinya, dimana organisasi perlu berkembang menjadi lebih efisien dan bersaing lebih agresif. Dengan adanya pengembangan organisasi tersebut memungkinkan bagi karyawan terdorong untuk lebih giat dalam melakukan pekerjaan. Seorang karyawan berharap dengan adanya pengembangan organisasi, maka kesejahteraan akan ditingkatkan oleh organisasi sesuai dengan perkembangannya.

PG. Rejosari merupakan salah satu unit usaha dari PT. Perkebunan Nusantara IX (Persero) tentunya tidak lepas dari permasalahanpermasalahan yang berkaitan dengan motivasi kerja karyawan, maka penulis menyusun rencana penelitian tentang motivasi kerja PT. Perkebunan IX (Persero) PG. Rejosari Magetan, dengan judul penelitian: Dampak Dekruitmen, Mutasi, dan Pengembangan Terhadap Motivasi Kerja Karyawan PT. Perkebunan Nusantara IX (Persero) PG. Rejosari, Magetan.

\section{Tujuan Penelitian}

1. Untuk menganalisis pengaruh dekruitmen, mutasi, dan pengembangan organisasi terhadap motivasi kerja karyawan PT. Perkebunan Nusantara IX (Persero) PG. Rejosari, Magetan

2. Untuk menganalisis faktor yang paling dominan dalam mempengaruhi motivasi kerja 


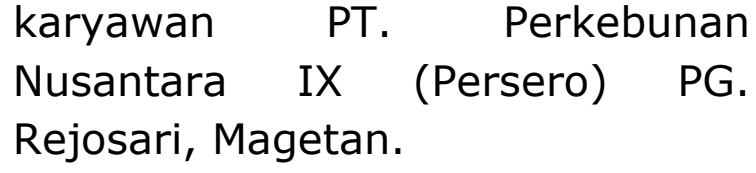

\section{TINJAUAN PUSTAKA}

\section{Motivasi}

Motivasi adalah keadaan dalam pribadi seseorang yang mendorong keinginan individu untuk melakukan kegiatan-kegiatan tertentu guna mencapai suatu tujuan. Dalam hal ini motif yang ada pada seseorang akan mewujudkan suatu tingkah laku yang diarahkan pada tujuan mencapai sasaran kepuasan. Jadi motif bukanlah sesuatu yang dapat diamati dan saksikan (Handoko, 2003: 77).

\section{Dekruitmen}

Dekruitmen

berhubungan

(decruitment) aktivitas yang dirancang untuk mengurangi suplai tenaga kerja di dalam organisasi atau pada bagiannya. Terdapat beberapa pilihan dekruitmen yang terbuka bagi organisasi. Pemberhentian (layoff) diartikan bahwa sebuah organisasi memberhentikan individuindividu atau kelompok-kelompok dari posisi mereka untuk jangka waktu pendek, menengah, atau panjang. Pengurangan karyawan (attrition) menunjuk kepada memungkinkan tenaga kerja untuk berkurang secara alamiah, sepanjang waktu, sebagai akibat pengunduran diri karyawan dan pensiun. Transfer lateral (lateral transfer) diartikan sebagai perpindahan individu-individu dari satu pekerjaan ke pekerjaan yang lain dengan tanggung jawab yang berbeda tetapi pada level yang sama dalam hierarki organisasional. Transfer ke bawah (downward transfer) serupa dengan transfer lateral, kecuali posisi yang baru adalah lebih rendah dalam struktur organisasional. Pemecatan (firing) diartikan sebagai pemutusan hubungan kerja di luar kemauan karyawan, umumnya sebagai akibat masalah kinerja ataupun yang berhubungan dengan sikap karyawan (Simamora, 2004: 267).

\section{Mutasi}

Menurut Wursanto (2004: 65) mutasi adalah suatu kegiatan memindahkan pegawai dari unit/bagian yang kelebihan tenaga ke unit/bagian yang kekurangan tenaga atau yang lebih memerlukan. Mutasi atau pemindahan pegawai dapat terjadi karena dua hal, yaitu:
a. Keinginan pegawai sendiri, misalnya:

1). Pegawai yang bersangkutan merasa tidak sesuai dengan bidang tugasnya atau jabatannya;

2).Pegawai yang bersangkutan merasa tidak dapat bekerja 


sama dengan teman
sekerjanya atau dengan
atasannya;
. Pegawai yang bersangkutan
merasa bahwa tempat atau
lingkungan kerja tidak sesuai
dengan kondisi fisik atau
keinginannya.

b. Keinginan organisasi, dengan tujuan:

$\begin{array}{lr}\text { 1). Organisasi } & \text { ingin } \\ \text { menunjukkan kepada }\end{array}$ pegawai yang bersangkutan bahwa mutasi tersebut bukan merupakan hukuman, melainkan upaya untuk menjamin kelangsungan pekerjaan pegawai tersebut;

2). Organisasi ingin menyakinkan pegawai bahwa ia tidak akan diberhentikan karena kekurangmampuan atau kekurangcakapan pegawai yang bersangkutan;

3). Organisasi ingin menghindari rasa jenuh pegawai pada jenis pekerjaan, jabatan maupun tempat kerja yang sama.

\section{Pengembangan Organisasional}

Pengembangan organisasional didefinisikan sebagai penerapan ilmu pengetahuan tentang perilaku dalam usaha jangka panjang untuk meningkatkan kemampuan

$\begin{array}{lr}\text { organisasi } & \text { dalam menghadapi } \\ \text { lingkungan } & \text { eksternal dan } \\ \text { meningkatkan } & \text { kemampuan } \\ \text { pemecahan } & \text { masalah-masalah } \\ \text { internal. Jadi } & \text { pengembangan }\end{array}$
organisasional mengacu pada proses persiapan dan pengelolaan perubahan organisasi (yang terencana), dengan menerapkan berbagai prinsip ilmu pengetahuan tentang perilaku manusia. Tujuan akhir pengembangan organisasional adalah untuk mempertemukan tujuan organisasi, kelompok, dan individu, melalui peningkatan keefektifan, keadaptasian, ketrampilan, pemecahan masalah, kepekaan, dan partisipasi aktif para organisasi dalam seluruh aktivitas organisasi perusahaan. Tujuan pengembangan organisasi dapat dipecah menjadi tiga sub tujuan utama yaitu perubahan sikap atau nilai-nilai, modifikasi perilaku, dan perubahan struktur dan kebijakan (Suprihanto, 2003: 161).

\section{B. Penelitian Terdahulu}

1. Penelitian Hansen, 2003, Motivasi adalah suatu pemikiran untuk mengarahkan faktor kepribadian, faktor sosial, dan atau pengamatan yang diasumsikan dalam sebuah peran ketika seseorang mempunyai andil di dalam suatu tugas yang dievaluasi, menjadi 
suatu kompetisi dengan orang lain, atau usaha untuk mencapai standart keunggulan. Selebihnya motivasi sering dibagi setidaknya ada tiga tipe utama, intrinsik, ekstrinsik, dan amotivasi. Motivasi intrinsik digambarkan sebagai suatu aktivitas yang semata-mata bertujuan untuk suatu kesenangan atau kepuasan. Motivasi ekstrinsik merupakan pengarahan suatu aktivitas yang lebih mengarah pada manusia atau beberapa penghargaan eksternal. Amotivasi terjadi ketika pengalaman

seseorang merasakan ketidakcakapan dan kurang pengendalian. Mereka tidak lagi mempunyai alasan untuk berpartisipasi.

2. Emin, 2007. Hasil dalam penelitian ini adalah meneliti beberapa kombinasi variabel seperti umur, gender, pengalaman, waktu observasi dan kepribadian menjadi faktor besar dalam mempengaruhi penampilan tenaga kerja. Dalam investigasi diindikasi pengaruh dari tempat kerja dan penampilan kondisi kerja.

\section{Kerangka Pemikiran}

\begin{tabular}{|c|c|}
\hline Var. Independen & Var. Dependen \\
\hline $\mathrm{X} 1=$ Dekruitmen & \\
\hline $\mathrm{X} 2=$ Mutasi & Y - Mativaci \\
\hline $\begin{array}{l}\mathrm{X} 3 \text { = Pengembangan } \\
\text { organisasi }\end{array}$ & ker \\
\hline
\end{tabular}

\section{METODE PENELITIAN}

\section{Lokasi Penelitian}

Penelitian ini dilakukan di PT. Perkebunan Nusantara IX (Persero) PG. Rejosari, Magetan yang terletak di desa Gorang- gareng, Magetan.
Metode Pengambilan Data

Dalam penelitian ini penulis menggunakan dua macam data, yakni data primer yang diambil langsung dari sumbernya dengan menggunakan kuesioner dan data sekunder yang didapat dari data yang ada pada PT. 
Perkebunan Nusantara IX (Persero) PG. Rejosari, Magetan.

1. Sumber Data

a. Data Primer

Data primer adalah data yang dihasilkan dari jawaban angket yang masih berupa data asli yang diperoleh dari penelitian pada seluruh pegawai PT. Perkebunan Nusantara IX (Persero) PG. Rejosari, Magetan yang menjadi sampel dalam penelitian dan dokumen-dokumen yang ada kaitannya dengan penelitian ini yang didapat langsung dari PT. Perkebunan Nusantara IX (Persero) PG. Rejosari, Magetan;

b. Data Sekunder

Data sekunder adalah data yang diperoleh bukan dari penelitian langsung, melainkan hasil dari penelitian yang dilakukan oleh pihak lain. Data sekunder atau data penunjang dalam penelitian ini, bersumber dari studi pustaka seperti literatur/sumber lain yang ada hubungannya dengan penelitian dan informasi yang berasal dari pegawai PT. Perkebunan Nusantara IX (Persero) PG. Rejosari, Magetan yang dijadikan sampel.
2. Teknik Pengumpulan Data a. Observasi

Data yang dikumpulkan melalui pengamatan secara langsung terhadap obyek yang diteliti;

b. Kuesioner

Data yang dikumpulkan melalui penyebaran angket kepada pegawai PT. Perkebunan Nusantara IX (Persero) PG. Rejosari, Magetan, berupa pertanyaan dengan jawaban bersifat langsung

\section{Populasi dan Sampel}

Populasi dalam penelitian ini adalah seluruh pegawai PT. Perkebunan Nusantara IX (Persero) PG. Rejosari, Magetan yang berjumlah 460 orang. Mengingat besarnya jumlah populasi lebih dari 100 orang, maka dalam penelitian ini peneliti mengambil sampel sebesar $15 \%$ atau 69 sampel. Hal ini sesuai dengan pendapat Arikunto (2002:112) yang menyatakan bahwa apabila subyeknya kurang 100, lebih baik diambil semua sehingga penelitiannya merupakan penelitian populasi. Selanjutnya, jika jumlah subyeknya besar dapat diambil antara $10 \%$ $15 \%$ atau $20 \%$ - $25 \%$ atau lebih. Pengambilan sampel tersebut dilakukan dengan cara random sampling (acak). 


\section{PEMBAHASAN}

Alat analisis yang digunakan dalam penelitian ini adalah model regresi logistik binari yaitu model lain dari analisis regresi untuk menjelaskan pola pengaruh antara variabel independen dan dependen. Seperti yang sudah tersusun pada kerangka penelitian, bahwa variabel independen pada penelitian ini dekruitmen, mutasi, dan pengembangan organisasi.
Variabel dependen dalam penelitian ini menggunakan variabel motivasi kerja karyawan dengan skala biner (bernilai 0 dan 1). motivasi kerja karyawan dalam penelitian ini diukur dengan menggunakan ukuran efektif dan tidak efektif, sehingga dalam penelitian ini menggunakan satu model regresi logistik binari. Model regresi logistik binari dilakukan dengan menggunakan persamaan berikut ini:

$$
\begin{array}{ll}
Y=\beta_{0}+\beta_{1} X_{1}+\beta_{2} X_{2}+\beta_{3} X_{3}+v \\
\text { Dimana: } & \\
Y & =\text { Motivasi Kerja karyawan } \\
X_{1} & =\text { Dekruitmen } \\
X_{2} & =\text { Mutasi } \\
X_{3} & =\text { Pengembangan organisasi } \\
V & =\text { error }
\end{array}
$$

Setelah dilakukan estimasi dan berbagai uji dengan komputer hasilnya dapat disajikan seperti tabel berikut:

Tabel IV.8. Uji Koefisien Regresi Logistik Binari

\begin{tabular}{llll}
\hline \multicolumn{1}{c}{ Variabel } & $\mathrm{B}$ & Wald & $\mathrm{P}$ \\
\hline Dekruitmen $\left(\mathrm{X}_{1}\right)$ & 0,407 & $6,120^{* *}$ & 0,013 \\
Mutasi $\left(\mathrm{X}_{2}\right)$ & 0,454 & $5,841^{* *}$ & 0,016 \\
Pengembangan organisasi & 0,679 & $6,494 * *$ & 0,011 \\
$\left(\mathrm{X}_{3}\right)$ & & & \\
Konstanta & $-37,405$ & $11,401 * * *$ & 0,001 \\
\hline
\end{tabular}

Sumber Data diolah (2014)

Hasil data pengujian model regresi logistik binari dengan variabel dependen motivasi kerja karyawan (Y) diperoleh persamaan sebagai berikut. 


$$
\begin{array}{r}
\mathrm{Y}=-37,405+0,407 \mathrm{X}_{1}+0,454 \mathrm{X}_{2}+0,679 \mathrm{X}_{3} \\
(6,120)^{* * *} \quad(5,841)^{* *} \quad(6,494) * * *
\end{array}
$$

Keterangan:

$(\quad)=$ Menerangkan nilai wald

$* * *=$ Signifikan pada $\alpha=1 \%$

$* * \quad=$ Signifikan pada $\alpha=5 \%$

Persamaan di atas dapat ditafsirkan bahwa variabel dekruitmen, mutasi, dan pengembangan organisasi terhadap motivasi kerja karyawan di PT. Perkebunan Nusantara IX (Persero) PG. Rejosari, Magetan.

1. Uji Ketepatan Model Regresi

Dalam penelitian ini digunakan Hosmer and Lemeshow's Goodness of fit Test. Jika nilai Hosmer and Lemeshow Goodness of fit test statistik sama dengan atau kurang dari 0,05, maka hipotesis nol ditolak yang berarti ada perbedaan signifikan antara model dengan nilai observasinya. Sehingga Goodness fit model tidak baik karena model tidak dapat memprediksi nilai observasinya. Jika nilai statistic Hosmer's and Lemeshow Goodness of fit lebih besar dari 0,05, maka hipotesis nol tidak dapat ditolak dan berarti model mampu memprediksi nilai observasinya atau dapat dikatakan model dapat diterima karena cocok dengan data observasinya. Dari hasil penelitian SPSS diperoleh nilai Goodness adalah 5,173 dengan nilai signifikan sebesar 0,739 yang berarti $>0,05$. Hal ini menunjukkan bahwa model dapat diterima.

2. Uji Ekspektasi B Setelah dilakukan pengujian model regresi logistik binari terungkap bahwa prediktor yang tepat digunakan sebagai variabel untuk memprediksi motivasi kerja karyawan adalah variabel yang telah memberikan hasil yang signifikan yaitu dekruitmen, mutasi, dan pengembangan organisasi.

Nilai $\operatorname{Exp}(\mathrm{B}) \quad$ yang dilaporkan pada output SPSS dapat digunakan sebagai petunjuk untuk mengetahui 
DAMPAK DEKRUITMEN, MUTASI, DAN PENGEMBANGAN ORGANISASI

TERHADAP MOTIVASI KERJA KARYAWAN PT. PERKEBUNAN NUSANTARA IX

PERSERO) PG. REJOSARI MAGETAN

ISSN : 1412-6029X

besarnya kontribusi yang

diberikan masing-masing

variabel terhadap motivasi kerja

karyawan. Berdasarkan hasil

pengujian model regresi logistik

binari dipe
ekspektasi B
dari variabe
seperti nampak
dibawah

Sig
0,013
0,016
0,011

Sumber: Data diolah (2014)

Melihat besarnya nilai ekstektasi $B$ atau nilai $\operatorname{Exp}(B)$ diatas, menunjukkan bahwa variabel pengembangan organisasi mempunyai pengaruh yang lebih besar (nilai $\operatorname{Exp}(B)$ $=1,972$ ) terhadap motivasi kerja karyawan dibandingkan variabel dekruitmen dan mutasi. Hal ini menunjukkan, bahwa variabel pengembangan organisasi memberikan kontribusi yang paling besar dibandingkan variabel lain.

B. Analisis Motivasi Kerja

Hasil koefisien regresi logistik diketahui bahwa semua variabel independen berpengaruh signifikan terhadap variabel motivasi kerja karyawan. Menurut prediksi karyawan yang merasa memiliki motivasi rendah dengan kode nol (0) adalah 16 responden, sedangkan observasi keseluruhan sebanyak 19. Jadi ketepatan klasifikasi $\quad 84,2 \% \quad(16 / 19)$, sedangkan prediksi karyawan yang merasa memiliki motivasi tinggi dengan kode satu (1) ada 48 responden, sedangkan hasil observasi keseluruhan sebanyak 50 jadi ketepatan klasifikasi $96 \%$ $(48 / 50)$ atau secara keseluruhan ketepatan klasifikasi adalah $92,8 \%(92,8 / 100)$.

\section{KESIMPULAN DAN SARAN}

\section{A Kesimpulan}

Berdasarkan hasil analisis data dengan menggunakan analisis logistik binari, hasil penelitian dapat disimpulkan sebagai berikut:

1. Variabel dekruitmen, mutasi, dan pengembangan organisasi 
mempunyai pengaruh yang positif dan signifikan terhadap motivasi kerja, yang ditunjukkan dengan nilai chi square Hosmer and Lemeshow Test sebesar 5,173 dan nilai sig Hosmer and Lemeshow test yang sebesar 0,739;

2. Variabel

pengembangan organisasi memberikan sumbangan pengaruh yang paling besar terhadap motivasi kerja dibandingkan dengan variabel dekruitmen dan mutasi, hal ini ditunjukkan dengan nilai koefisien beta sebesar 0,679 dan nilai ekspektasi B sebesar 1,972 .

\section{B Saran}

Pengembangan organisasi
berdasarkan hasil penelitian
ternyata mampu memberikan
pengaruh terhadap motivasi kerja,
untuk itu disarankan agar
perusahaan dapat memberikan
informasi kepada karyawan
tentang rencana pengembangan
organisasi. Dengan diketahuinya
rencana pengembangan organisasi,
maka setiap karyawan akan
mempunyai harapan untuk lebih
baik. Dengan r adanya
pengembangan arganisasi
dimaksudkan agar perusahaan
dapat meningkatkan kualitasnya
dan dapat mengembangkan

Hal-hal yang terkait dengan dekruitmen perlu diinformasikan secara transparan, sehingga setiap karyawan mempunyai motivasi untuk meningkatkan kualitas kerjanya dengan harapan dekruitmen atau pengurangan karyawan. Mutasi dilakukan oleh pihak perusahaan dengan maksud untuk memberikan suasana baru dan untuk mengatasi dari rasa bosan dalam melaksanakan tugas sehingga dapat lebih termotivasi dalam melaksanakan tugas yang telah dibebankan kepadanya. dari sekarang. perusahaan tidak akan melakukan 


\section{DAFTAR PUSTAKA}

Arikunto, Suharsimi, 2002, Prosedur Penelitian Suatu Pendekatan Praktek, PT, Rineka Cipta, Jakarta;

Evison, Tom, Read, D. Adam, 2001, "Local Authority recycling and wasteawareness publicity/promotion", Test Valley Borough Council, Environment and Health Services, Council offices, Duttons Road, Romsey, S051 8XG, UK, School of Earth Science and Geography, Kingston University, Penrhyn Road, Kingston upn Thames, Survey KTI 2EE, UK, Resources, Coservation and Recyling;

Gautier, Pieter A., 2002, "Non sequential search, screening externalities and the public good role of recruitment offices", Erasmus University, Rotterdam, The Netherlands, Tinbergen Institute, Keizersgracht 482, 1017 EG Amsterdam, The Netherlands, Economic Modelling;
Ghozali, Imam, 2001, Analisis Multivariate dengan program SPSS, Badan Peneribit Universitas Diponegoro, Semarang;

Handoko, T. Hani, 2003, Manajemen, Yogyakarta: BPFE;

Hansen, Brent, Wade Gilbert, Tim Hamel, 2003, Successful Coaches' Views on Motivation and Motivational Strategies, Journal of Physical Education, Recreation \& Dance, Academic Research Library;

Kahya, Emin, 2007, The effects of job characteristics and working conditions on job performance, Departement of Industrial Engineering, Eksisehir Osmangazi Univercity, Bademlik Campus, Eksisehir, Turkey, International Journal of Industrial Ergonomics;

Kominis, George, Emmanuel, Clive R., 2006, The expectancy-valence theory revisited: Developing an extended model of managerial motivation, Departemen of Accounting \& Finance, University of Glasgow, UK, Management Accounting Research; 
Kuncoro, Mudrajad, 2003, Metode Riset Untuk Bisnis dan Ekonomi, Erlangga, Jakarta;

Samsudin, Sadili, 2006, Manajemen Sumber Daya Manusia, CV.

Pustaka Setia, Bandung;

Simamora, Henry, 2004, Manajemen Sumber Daya Manusia, STIE YKPN, Yogyakarta;

Sugiyono, 2003, Metode Penelitian Administrasi, Bandung: Alfabeta;

Suprihanto, John, Harsiwi M., Agung, Hadi, Prakosa, 2003, Perilaku Organisasional, Yogyakarta: Sekolah Tinggi Ilmu Ekonomi YKPN;

Uno, Hamzah B., 2007, Teori Motivasi dan Pengukurannya Analisis di Bidang Pendidikan, Jakarta: PT. Bumi Aksara;

Wahyuddin, M., 2004. Industri dan Orientasi Ekspor: Dinamika dan analisis Spasial, Muhammadiyah University Press. Surakarta;

Wursanto, 2004, Manajemen Kepegawaian 1, Penerbit Kanisius, Yogyakarta 